\title{
A RARE CASE OF BIFID PENIS WITH IMPERFORATE ANUS
}

Sharan Deshmukh' ${ }^{1}$, Shrikant S. W' ${ }^{2}$, Sharangouda Patil ${ }^{3}$, Harilal Naik M. L ${ }^{4}$

\section{HOW TO CITE THIS ARTICLE:}

Sharan Deshmukh, Shrikant S. W, Sharangouda Patil, Harilal Naik M. L. "A Rare Case of Bifid Penis with Imperforate Anus". Journal of Evolution of Medical and Dental Sciences 2014; Vol. 3, Issue 48, September 29; Page: 11614-11616, DOI: $10.14260 /$ jemds/2014/3523

ABSTRACT: BACKGROUND: Diphallus is rare anomaly \& accompanying anomalies vary from bifid scrotum, bladder exstrophy, imperforate anus and colo-rectal anomaly such as duplication, and other associated anomalies. We report a case of 2 day old newborn who had bifid penis, bifid scrotum with imperforate anus.

KEYWORDS: Diphallus, Imperforate Anus.

INTRODUCTION: Bifid penis is a rare anomaly and accompanying anomalies vary from imperforate anus, colorectal anomaly, bladder extrophy and others. Incidence is 1 in every 5 million live births.

CASE PRSENTATION: A 2 day old male newborn was brought us because of distended abdomen, abnormal genitalia \& imperforate anus. Thus antenatal history was uneventful, and investigations were negative for other associated anomalies postnataly.

The birth history was normal. It is a consanguineous marriage. Examination of genitalia revealed a well formed double penis, functioning urethra, bifid scrotum with each compartment containing a testicle. Perineal examination showed imperforate anus.

The values of blood analysis were within normal limits. Postoperatively abdominal ultrasonography showed bilateral normal kidneys. The day after he underwent colostomy, we performed an intravenous pyelography which showed normal kidneys and urethra. It was diagnosed as high lining recto urethral fistula.

DISCUSSION: Diphallus or duplication of the penis is rare anomaly that occurs 1 in every 5 million live births. ${ }^{1}$ They may be associated with different anomalies such as anorectal malformation and lower genitourinary abnormalities. ${ }^{2}$ Azmy has reported complete duplication of the hindgut which had two anal openings and a lower urinary tract with diphallus. ${ }^{3}$

The first case was reported in 16094. Schneider classified diphallus in three groups; diphallus of glans alone, bifid diphallus, and complete diphallus. Vilanova and Raventos have added a fourth category pseudodiphallus. ${ }^{1,4}$ The meatus may be normal, epispadic or hypospadic and the scrotum may be normal or bifid 5 Treatment of diphallususually includes excision of the duplicated penile structure and its urethra.1,6 Associated congenital anomalies are present in majority of the cases. ${ }^{1,3,7}$ 


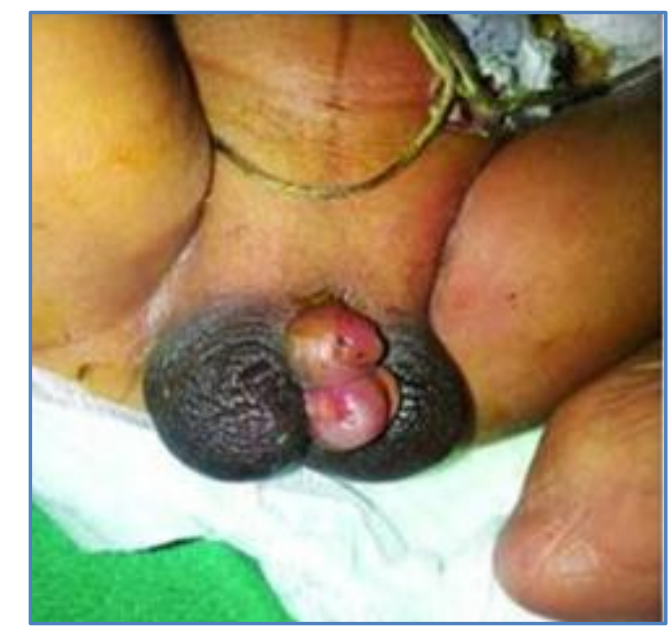

Fig: Bifid Penis and Bifid Scrotum

CONCLUSION: The babies with diphallus though have a rare incidence have to be examined carefully because of the high incidence of other systemic anomalies. Treatment includes excision and repair of associated anomalies.

\section{REFERENCES:}

1. Abdulkadir T, Mert A, Unsal O, et al. Complete diphallus in a 14 year old body. Marmara Med. J. 207; 20 (3): 19102.

2. Sarin YK, Manchanda V, Sharma A, et al. Triplication of colon with diphallus and complete duplication of bladder and urethra. J Pediatr Surg. 2006; 41 (11): 19246.

3. Azmy AF. Complete duplication of the hindgut and lower urinary tract with diphallus. J Pediatr Surg. 1990; 25 (6): 6479.

4. Vilanova X, Raventos A. Pseudodiphallia a rare anomaly, J Urol. 1954; 71: 33846.

5. Altug U, Cakam M, Yalcinkay F. Evaluation and reconstruction of an extremely rare gentitourinary abnormality. Intr Urol Nephrol. 2007; 39: 1913.

6. Carvalho AP, Ramires R, Soares J, et al. Surgical treatment of complete penile duplication. Actas Urgol ESP. 208; 32 (9): 9414. 


\section{CASE REPORT}

\section{AUTHORS:}

1. Sharan Deshmukh

2. Shrikant S. W.

3. Sharangouda Patil

4. Harilal Naik M. L.

\section{PARTICULARS OF CONTRIBUTORS:}

1. Post Graduate, Department of Paediatrics, M. R. Medical College, Gulbarga.

2. Professor \& Vice Principal, Department of Paediatrics, M. R. Medical College, Gulbarga.

3. Associate Professor and HOD, Department of Paediatrics, M. R. Medical College, Gulbarga.

4. Post Graduate, Department of Paediatrics, M. R. Medical College, Gulbarga.

\section{NAME ADDRESS EMAIL ID OF THE CORRESPONDING AUTHOR:}

Dr. Sharan Deshmukh,

H. No. 1-1156/12 (4),

Aiwan E Shahi Colony,

PDA College Road,

Gulbarga-585102.

Email: deshmukhsharan1@gmail.com

Date of Submission: 04/09/2014.

Date of Peer Review: 05/09/2014.

Date of Acceptance: 22/09/2014.

Date of Publishing: 29/09/2014. 